\title{
Service Productivity and Complexity in Medical Rescue Services
}

\author{
Markus Harlacher*, Andreas Petz, Philipp Przybysz, Olivia Chaillié, Susanne Mütze-Niewöhner \\ Institute of Industrial Engineering and Ergonomics, Work Organization Department, RWTH Aachen University, \\ 52062 Aachen, Germany
}

\begin{tabular}{l} 
A R T I C L E I N F O \\
\hline Article history: \\
Received: 05 April, 2017 \\
Accepted: 07 May, 2017 \\
Online: 24 May, 2017 \\
\hline
\end{tabular}

Keywords:

Service Productivity

Service Complexity

Construct Reliability

Construct Validity

\begin{abstract}
A B S T R A C T
The increasing impact of services on economic wealth and income in high-wage countries calls for a detailed examination of service productivity and complexity in current research projects. This paper describes the development of a measurement model of service productivity and complexity within the domain of medical service provision. While the measurement model of service productivity is partly literature-based, a novel construct is developed for service complexity. The reliability and validity of these constructs have been analyzed by a survey with 454 employees of German medical rescue service providers. Reliability of the construct is estimated by analyzing Cronbach's alpha, average variance extracted, variance inflation factors and the significance, weights and loadings of the items. Furthermore, the relationship between the partial productivities (capacity, internal and external) as well as complexity and service performance is analyzed by using the structural equation modeling approach with partial least square method (PLS-SEM). The results indicate that the developed constructs have sufficient reliability, although the examination of validity highlights difficulties in quantifying service productivity and complexity. While a significant and substantial effect of internal and external efficiency on service performance could be proved, complexity influences performance only marginally and positively while capacity efficiency has no effect at all. Thus, further research is needed in order to foster the measurement model and to investigate possible nonlinear relationships between the constructs in more detail.
\end{abstract}

\section{Introduction}

\subsection{Service Productivity and Complexity}

The service sector represents the largest part of the economy in the majority of the developed countries. In Germany, the tertiary sector's proportion of the gross domestic product (GDP) was $69 \%$ in 2015 . In the US, the proportion was even higher, reaching $78 \%$. This highlights the importance of services in overall economy [1]. Focusing the impact services have on economic growth, employment and international competitiveness, scientific studies are essential for a comprehensive understanding of service productivity and complexity [2].

"Corresponding Author: Markus Harlacher, Bergdriesch 27, 52062 Aachen, Germany | Email: m.harlacher@iaw.rwth-aachen.de

www.astesi.com

https://dx.doi.org/10.25046/aj020355
In previous research [3-6] different models describing service productivity and complexity were developed. Thus, different ways to operationalize service productivity were assessed. Based on these results, service productivity and complexity within the domain of medical services are discussed in this paper.

\subsection{Rescue Services and Electric Mobility}

Due to technological advances in electric mobility, changes in process of provision of emergency services are inevitable. Ambulance services are not only essential for society, they also occur with a high frequency. During 2012/2013 there were more than 14 million rescue missions in Germany. More than 270,000 rescue missions were caused by traffic accidents [7]. Driven by technological change and growing environmental awareness as 


\section{Harlacher et al. / Advances in Science, Technology and Engineering Systems Journal Vol. 2, No. 3, 427-434 (2017)}

well as falling prices the number of electrically-powered vehicles increases. In consequence, the increasing number of electric mobility vehicles in road traffic will affect the provision process of ambulance services. For example, the measures to guarantee the personnel protection in road traffic accidents will be more challenging and more varied caused by the higher number of vehicle variants. Moreover, novel injury patterns will occur in the context of road traffic accidents. These changes in service provision must be examined and the employees need to be sufficiently and appropriately trained for safe rescue missions with electric vehicles. Thus, higher acceptance of electric mobility can be reached.

\subsection{Objectives and Structure}

This paper aims to empirically measure and evaluate the relationship between service productivity and complexity and the effect on medical rescue service performance. For this purpose, a measurement model of service productivity and complexity is developed. Furthermore, reliability and validity of the measurement model is assessed by specific criteria. Following the findings, the process of the rescue service can be adapted for increasing service productivity and performance.

The paper is structured as follows: First, a literature based definition of service productivity and complexity is given. The hypotheses and the study design are presented in chapter 3 . The model evaluation in chapter 4 is divided in the measurement model evaluation focusing reliability and validity and structural model evaluation focusing on testing the hypotheses. The results and the limitations of this study are discussed in chapter 5. Finally, key findings for practitioners and academia are presented.

\section{Literature Review}

\subsection{Defining Service Productivity}

Starting point of any productivity measure is the goods-based definition of productivity as the ratio of output to input. It measures the performance of the operational factor combination: e.g. number of vehicles produced in one hour. Usually traditional performance indicators of productivity are made out of the same physical dimensions in numerator and denominator. Due to specific characteristics of services like customer integration and their immediate effect on productivity and complexity the traditional concept of productivity is too narrow. Researchers have proposed different concepts for service specific productivity evaluation and service system design.

Production-oriented approaches go back to Levitt [8] and Jones [9] as well as Corsten [10]. They define partial productivities in different, subsequent stages of service provision focusing on capacity utilization and one sided, technical quality management. A more comprehensive view was taken by Johnston and Jones [11] as well as Grönroos and Ojasalo [4]. Grönroos and Ojasalo define service productivity as a function of three elementary measures of performance [4]:

1. Efficiency of transforming input resources to output result for the customer (internal efficiency)

2. Perception of the quality of the service process and of the outcome (external efficiency)
3. Efficiency of utilizing the capacity of the service process (capacity efficiency)

Customer integration and internal processes were identified as the relevant influencing factors of internal efficiency. Customer satisfaction as well as corporate and customer benefits are key figures of external efficiency. Finally, quantitative and qualitative congruence (accordance of supply and demand) defines the core of capacity efficiency $[5,6]$.

\subsection{Defining Service Complexity}

Complex services, like emergency medical services, consist of a variety and diversity of interdependent system elements [5]. Service complexity as the property of these elements assumes a variety of emergent states in a defined period of time [12]. This in turn causes variety, makes complex services hardly predictable and uncertain in their behavior [13].

Blockus [14] defines service complexity as the characteristic of the system "service provider" concerning the variety, diversity, interdependencies and dynamic of the three dimensions of service: potentials, processes and outcomes. The "service potential" dimension describes the resources of a service provider for fulfilling the demand for services. Considering Bruhn and Georgi [15] these particularly involve the employees with their administrative and operative abilities, capacities and their qualifications including applied technologies and physical environment such as subsidiaries, information leaflets and blank forms.

The "service processes" dimension includes the complexity of direct and indirect processes of service provision as well as the autonomous customer process. The direct processes regard the actual service provision taking customer into account. The indirect processes are supporting processes as planning and procuring the resources or marketing the services. Autonomous customer processes are to be executed by the customer without direct involvement of the service provider. Moreover, the service processes dimension considers the complexity of external factors. External factors are characterized by not being predictable and influenceable by the service provider. These include the customer itself, its mobile and immobile properties as well as necessary permissions and information for service fulfillment. [14]

The "service outcomes" dimension refers to service results, which can be sold as market products. It considers the complexity of the applied service portfolio and of the single investigated service itself. [14]

\section{Method}

\subsection{Study Design}

The data for testing the hypothesized relationships were gathered by a questionnaire survey. 454 persons employed in the knowledge-intensive medical rescue service sector in Germany participated in the survey. A structural equation modeling method (SEM) was used for statistical analysis of the service productivity model. An empirical validation study was carried out and analyzed using partial least squares (PLS) path modeling as well as SPSS (v.21) for data preparation, data cleaning and descriptive statistics. The measurements and the structural model were analyzed using the SmartPLS 3 software package [16]. 


\subsection{Hypotheses}

Productivity describes the relation between process result and its means deployed. Considering the economical definition of productivity, service productivity and service performance are correlated positively. Thus, measures of efficiency should also correlate positively with service performance. The influence of the single efficiencies still remains uncertain.

An increasing internal efficiency means transforming input to output by minimizing input while maintaining the output or maximizing output while keeping inputs constant [11]. Thus service productivity increases and we posit:

$\mathrm{H}_{1}$ : Increasing internal efficiency positively influences service performance.

The better the perceived quality by using a specific amount of input resources, the better is the external efficiency, which results in an improved service performance. A decreasing perceived quality in turn causes a lowered "revenue-generating capability" which has a negative impact on service performance. [17]. Therefore hypothesis 2 is as follows:

$\mathrm{H}_{2}$ : Increasing external efficiency positively influences service performance.

The capacitive efficiency correlates positively with service productivity up to its optimum - demand equal to supply - because the costs for resources decrease for a single service. Assuming that service capacities in rescue services can only be overloaded in extreme situations (as they are highly important for society safety), overloaded resources should not affect the quality of service performance negatively [17]. Thus hypothesis 3 implies:

$\mathrm{H}_{3}$ : Increasing capacitive efficiency influences service performance positively.

A high complexity implies more procedures for handling it [18]. These extra activities disturb the working process and thus reduce service performance. Therefore hypothesis 4 can be derived as follows:

$\mathrm{H}_{4}$ : High complexity due to increased electro mobility influences service performance negatively.

\subsection{Questionnaire}

In order to operationalize the constructs items were formulated based on existing questionnaires as well as on literature on the dimensions of complexity [4-6]. Items were formulated and evaluated in semi-structured interviews with a group of experts. Furthermore, a pre-test was conducted for optimization purpose.

The structure and content of the questionnaire are depicted in Figure 1. The questionnaire can be divided into four parts. The first two parts collect personal and organization-specific information. The third part deals with already gained experience concerning electric mobility and expected problems caused by increased number of licensed electric vehicles with impact on service productivity and complexity. Finally respondents were asked to evaluate their performance regarding service productivity and complexity in the fourth part.

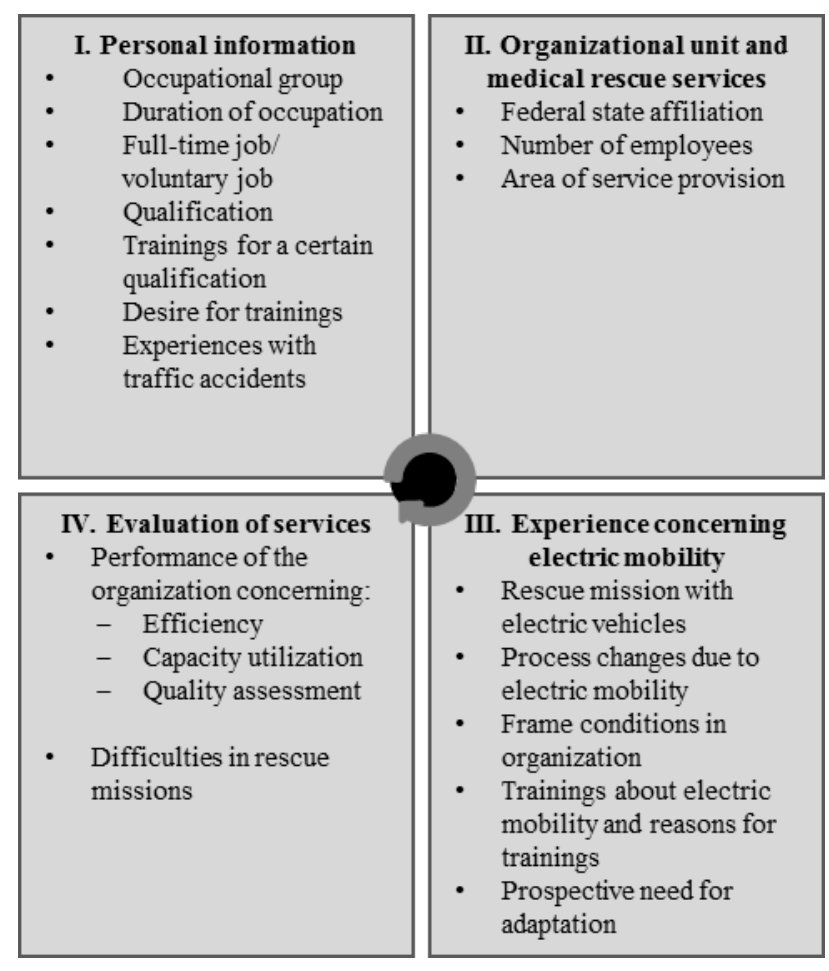

Fig. 1. Structure of the questionnaire.

\section{Measurement Model of Service Productivity}

In order to operationalize the constructs of service productivity 12 items were formulated based on the work of Grönroos and Ojasalo and Garrel et al. $[4,6]$. In summary, there are five items that quantify internal efficiency. Customer integration is operationalized by an item assessing whether frequent interactions with involved parties in accidents takes place without problems. Quality of internal processes is measured by the following statements:

1. The rescue mission is predominantly smooth.

2. There are delays in the rescue mission caused by insufficient technical equipment.

3. Rescue teams always get the most recent information to fulfill the task.

4. The work structure (e.g. authority and decision making) enables an interference-free operation.

External efficiency is measured by four items. Two items assess customer satisfaction regarding the level of medical and psychological care during the rescue mission. Organizational and customer benefit is mapped by items addressing the level of standardization of the procedures during the rescue process as well as by the aspect of achieving the target time. The operationalization of the quantitative congruence includes bottlenecks due to technical equipment. The qualitative congruence is operationalized by the following items:

1. Problems occur due to unavailability of sufficiently trained employees.

2. The technical equipment is optimized for the tasks of ambulance service. 


\section{Measurement Model of Service Complexity}

The results of the pre-test did not confirm a differentiation into the three dimensions of potential, process and outcome complexity. Thus, the measurement model of service complexity was revised in the final questionnaire. In order to assess complexity, rescue service processes of accidents with electric vehicles were compared to rescue service processes of accidents with conventional vehicles. Service complexity was measured by the following items:

1. Known algorithm can be used at car accidents with an e-car.

2. It is more difficult to ensure occupational safety on rescue missions with electric vehicles.

3. Handling electrical vehicles in accidents is more ambitious than handling conventional vehicles.

All items were answered on a six-point Likert scale. The response format ranged from 'Does not apply at all' (1) to 'Does fully apply' (6). For assessing the quality of the measurement model, both models of productivity and complexity were analyzed by means of correlation, reliability, and validity.

\subsection{Participants}

The nationwide survey was conducted online as well as paperbased on training events for rescue personnel. In total, 454 persons have completed the questionnaire. The majority completed the paper-based version of the survey. Less than 150 participants completed the online version, which was promoted solely within the organizations of the project partners (especially Red Cross Germany and the Interdisciplinary Training Center for Medical Education in Aachen).

$65.4 \%$ of the subjects were directly involved in the medical care of casualties. The majority of them were paramedics and emergency physician. More than $20 \%$ of the participants were firemen focusing the technical aspects of rescue. The remaining subjects held an administrative position in a rescue service organization.

About $75 \%$ of the participants were employed in rescue service as their main profession. Most subjects had work experience of more than two years, therefore a sufficient level of experience in rescue services can be assumed. $10 \%$ of the participants were already previously involved in a traffic accident with electricpowered vehicles. Given the market share of electric cars of only $.4 \%$ in Germany, the quota of respondents with electric-powered vehicle experience surpasses the expectations on the survey [19].

\section{Model Evaluation}

For model validation, we considered empirical measures of the relationships between the proposed indicators and constructs as well as between the constructs. We also evaluated the measurement model by means of reliability and validity.

\subsection{Measurement Model Evaluation}

The questionnaire used in the survey was based on previous research of Garell et al. [6]. The items used to measure the latent variables were defined as reflective and reliability was analyzed accordingly.
The formal accuracy of the model is assessed by Cronbach's alpha. The results of the reliability analysis of the measurement model of service productivity are visualized in Figure 2. Only external efficiency exhibits a sufficient reliability. Cronbach`s alpha of the total measurement model of service productivity achieves an unsatisfactory value of 407 .

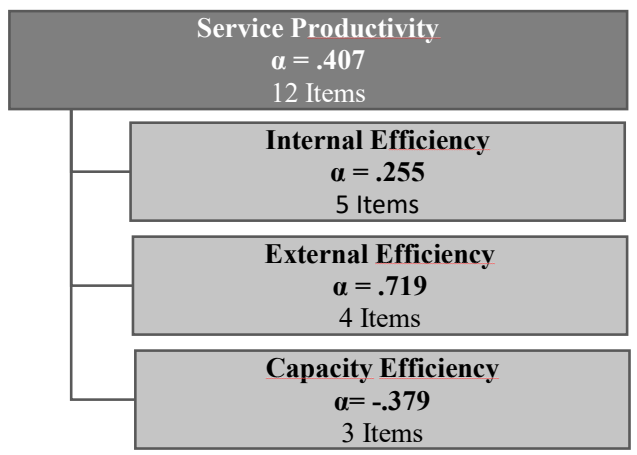

Fig. 2. Cronbach's alpha of the construct service productivity.

Due to the unsatisfactory results of the reliability analysis we examined a formative model as well. Based on the definition of the constructs it seems likely, that while adapting the constructs for the field of medical rescue services the cause-effect-relationship between items and construct changed. Therefore a confirmatory factor analysis is unsuitable. Thus, the structural equation modelling (PLS-SEM) approach is adopted. By using this method we can evaluate the multiple dependencies between productivity, complexity, and actual performance of medical rescue services.

For model validation, we considered empirical measures of the relationships between the proposed indicators and constructs as well as between the constructs. We also evaluated the measurement model by means of reliability.

First, the single reflective measured variable of the self-assessed service performance was analyzed. In order to do so, we looked at composite reliability for evaluating internal consistency. Individual indicator reliability and convergent validity where evaluated by average variance extracted and predictive relevance [20]. Discriminant validity was not investigated due to the fact that the latent variable service performance is the only reflective operationalized construct in the model, so a comparison with other variables is not possible.

Internal consistency reliability is usually measured by Cronbach's alpha. However, due to the PLS-SEM method, the preconditions for applying Cronbach's alpha (equal outer loadings of the indicators) were not satisfied. Thus, composite reliability $\left(\rho_{c}\right)$ was used instead. Composite reliability can vary between zero and one, with a high value indicating high reliability. An acceptable level of .6 to .7 in exploratory research is regarded as satisfactory [20]. The composite reliability of the performance is .635 , hence slightly above the required .6. This argues for sufficient internal consistency (measuring the same construct) in the proposed indicators of the self-assessed performance.

Individual indicator reliability is evaluated by the indicators' outer loadings. Their outer loadings should be .7 or higher [20]. In our study, two of three loadings were significantly above .7, thus revealing high individual reliability. For convergent validity, we 


\section{Harlacher et al. / Advances in Science, Technology and Engineering Systems Journal Vol. 2, No. 3, 427-434 (2017)}

considered average variance extracted (AVE). AVE evaluates communality not for a single item but for the whole construct, analogous to individual indicator reliability. AVE indicates the degree to which a construct explains the variance in the indicators. In our study, AVE accounted .44, so the construct explains more than $40 \%$ of variance. Table 1 summarizes the results of the assessment.

Table 1. Criteria for reflective measurement model evaluation

\begin{tabular}{lllll}
\hline Items & & $\mathbf{\rho}_{\mathbf{c}} \geq \mathbf{. 6}$ & AVE $\geq .5$ & $\lambda \geq \mathbf{0 , 7}$ \\
\hline & $\begin{array}{l}\text { Self-assessed service } \\
\text { performance }\end{array}$ & $\mathbf{. 6 6 3}$ & $\mathbf{. 4 4}$ & \\
\hline Perf_1 & Please estimate the workload of your organization. & .723 \\
\hline Perf_2 & $\begin{array}{l}\text { Please estimate the efficiency of your organization. } \\
\text { Perf_3 }\end{array}$ & $\begin{array}{l}\text { Please estimate the quality of the performance of your } \\
\text { organization as measured by the standard treatment } \\
\text { methods (e.g. "Golden Hour", ETC, PHTLS, ITLS). }\end{array}$ & .887 \\
\hline
\end{tabular}

The majority of the latent variables were operationalized using formative indicators. Compared to reflective indicators, formative indicators define the latent variable as a whole. The indicators describe and specify the content of the construct in a logical manner according to the underlying theory. Formative indicators are the source of the latent construct and therefore are not necessarily intercorrelated. They complement each other within the construct and form a self-contained variable. Thus, reliability measures are inappropriate for evaluating the goodness of the formative measurement model. Instead, content validity is evaluated by collinearity, significance and relevance of the indicators, and discriminant validity at the construct level [20,21].

Before the relationship and the predictive relevance of the model can be analyzed, the collinearity of the latent variables should be evaluated. In contrast to reflective indicators, where high levels of collinearity between indicators are important, in the case of formative indicators this is counterproductive because they increase standard errors and influence weight estimation negatively. In order to evaluate collinearity, we considered the variance inflation factor (VIF). The square root of the VIF is defined as the degree to which the standard error increases due to collinearity. Removing indicators should be considered in cases where the VIF value is higher than 5 [21]. All of the indicators analyzed showed an acceptable degree of collinearity $(\mathrm{VIF}<5)$. Thus, all items were considered for further analysis.

To evaluate the relevance of formative measures, we considered the outer weights of the indicators. In the proposed measurement model, 7 out of 15 items have a significant weight at a significance level of $\alpha=.1(t=1.65)$. Second, we also evaluated the significance of the outer loadings. After analyzing the outer loadings, only 3 out of 15 indicators proved to be non-significant. Two of the items measure complexity and one capacity efficiency. Considering the acceptable degree of collinearity, we retained the items in the model in order to preserve the logical, content-oriented composition of the constructs.

At the construct level, we considered discriminant validity by evaluating the correlations between the latent variables. Scores should be below .9 to ensure that no substantial relationship between different constructs exists [21]. All latent variables were found to be below the given limit. The highest correlation between internal efficiency and external efficiency of provided service (.57) is reasonable and in line with the content. A highly selective specification of the constructs is desirable but not practicable.

Table 2. Criteria for formative measurement model evaluation

\begin{tabular}{|c|c|c|c|c|}
\hline \multicolumn{2}{|l|}{ Items } & \multicolumn{2}{|c|}{$\begin{array}{r}\text { VIF }<5 \text { weight } \\
t>1,65\end{array}$} & \multirow{2}{*}{$\begin{array}{l}\text { loading } \\
\mathbf{t}>1,65\end{array}$} \\
\hline \multicolumn{4}{|c|}{ Complexity } & \\
\hline Comp_1_ & $\begin{array}{l}\text { RKnown algorithm can be used at car accidents } \\
\text { with an e-car. }\end{array}$ & 1.015 & 6.172 & 5.806 \\
\hline Comp_2 & $\begin{array}{l}\text { It is more difficult to ensure occupational } \\
\text { safety on rescue missions with electric } \\
\text { vehicles. }\end{array}$ & 1.404 & .223 & .124 \\
\hline \multirow[t]{2}{*}{ Comp_3 } & $\begin{array}{l}\text { Handling of electrical vehicles in accidents is } \\
\text { more ambitious than handling of conventional } \\
\text { vehicles. }\end{array}$ & 1.395 & .438 & .362 \\
\hline & Capacity Efficiency & & & \\
\hline CE_1_R & $\begin{array}{l}\text { Problems occur due to unavailability of } \\
\text { sufficiently trained employees. }\end{array}$ & 1.227 & 7.846 & 1.903 \\
\hline CE_2 & $\begin{array}{l}\text { The technical equipment is optimized for the } \\
\text { tasks of ambulance service. }\end{array}$ & 1.324 & 1.325 & 1.604 \\
\hline \multirow[t]{2}{*}{ CE_3_R } & $\begin{array}{l}\text { There are always bottlenecks with the technical } \\
\text { equipment. }\end{array}$ & 11.436 & .297 & 1.798 \\
\hline & Internal Efficiency & & & \\
\hline IE_1 & The rescue mission is predominantly smooth. & 1.242 & 4.354 & 10.600 \\
\hline IE_2_R & $\begin{array}{l}\text { There are delays in the rescue mission caused } \\
\text { by insufficient technical equipment. }\end{array}$ & 1.035 & 1.648 & 2.884 \\
\hline IE_3 & $\begin{array}{l}\text { Rescue teams always get the most recent } \\
\text { information to fulfill the task. }\end{array}$ & 1.329 & .781 & 5.106 \\
\hline IE_4 & $\begin{array}{l}\text { The work structure (e.g. authority and decision } \\
\text { making) enables an interference-free operation. }\end{array}$ & 1.430 & 5.636 & 13.758 \\
\hline \multirow[t]{2}{*}{ IE_5 } & $\begin{array}{l}\text { The inclusion of other participants (e.g. } \\
\text { patients, eyewitnesses, emergency responder) } \\
\text { into the rescue process is unproblematically. }\end{array}$ & 1.228 & .117 & 3.677 \\
\hline & External Efficiency & & & \\
\hline EE_1 & The patient can be treated satisfactorily. & 1.690 & 3.060 & 11.317 \\
\hline EE_2 & $\begin{array}{l}\text { We try to rescue crashed persons with } \\
\text { standardized procedures. }\end{array}$ & 1.632 & 4.402 & 18.146 \\
\hline EE_3 & $\begin{array}{l}\text { We always manage to keep the planned times } \\
\text { (reaching the place of the accident). }\end{array}$ & 1.283 & 1.235 & 5.454 \\
\hline EE_4 & $\begin{array}{l}\text { The patients (eyewitnesses, emergency } \\
\text { responder) feel excellently looked after during } \\
\text { the rescue. }\end{array}$ & 1.306 & 5.017 & 3.740 \\
\hline
\end{tabular}

\subsection{Structural Model Evaluation}

After the measurement model has been evaluated as reliable and valid, the structural model can be assessed accordingly. The structural model is evaluated by the relevance and significance of path coefficients, the coefficient of determination $\left(\mathrm{R}^{2}\right)$, effect size $\left(\mathrm{f}^{2}\right)$ and predictive relevance $\left(\mathrm{Q}^{2}\right)[20,21]$. By analyzing the path 


\section{Harlacher et al. / Advances in Science, Technology and Engineering Systems Journal Vol. 2, No. 3, 427-434 (2017)}

coefficient, we examined the hypothesized relationships. The posited relationships were assessed according to the magnitude, significance, and direction of the effect. The results are shown in Figure 3. The path coefficients can take values between -1 and 1 , with values close to \pm 1 representing a strong positive/negative relationship and values close to or equal to 0 indicating no relationship. In addition, the significance is evaluated by computing t-values with the help of the bootstrapping procedure. Based on the t-value, the probability of error is calculated, with t-values of 1.65 (10\% probability of error) and above considered to be significant. The results show that three out of four postulated relationships were significant. All significant relationships were found to be positive.

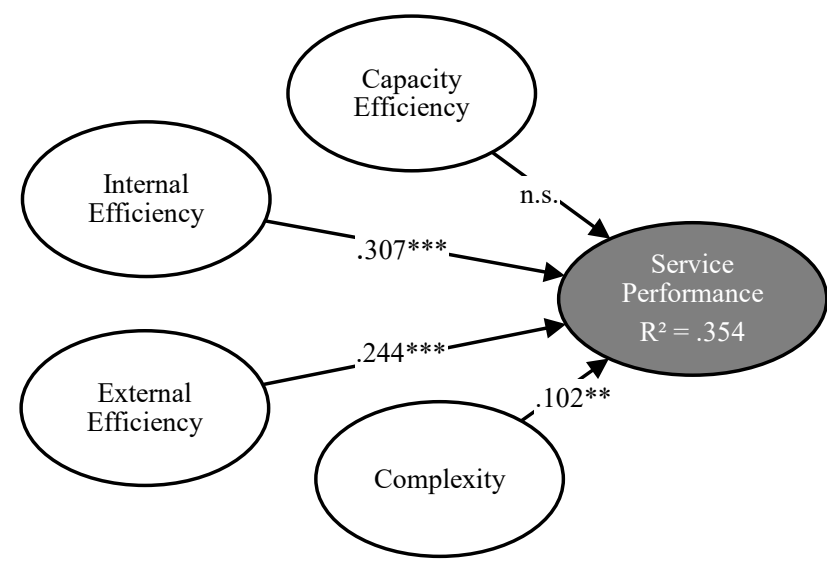

Fig. 3. Path coefficients and probability of error for the structural equation model of medical rescue service performance. ${ }^{* * *} \mathrm{p}<.01 ; * * \mathrm{p}<.05 ; * \mathrm{p}<.1$

Thus, hypotheses 1 and 2 can be confirmed. No significant effects were found with regard to hypothesis 3 . Contrary to hypothesis 4 the examination of the relation between service complexity and service performance results in a positive interdependence. Bruhn and Blockus [5] explain these improvements of productivity with increased motivation and satisfaction of the employees. Up to a specific level complexity of the task can be motivating and can increase thus the service performance.

The model's predictive accuracy is evaluated by the coefficient of determination $\left(\mathrm{R}^{2}\right)$. This coefficient is defined as the squared correlation between a specific endogenous construct's actual and predicted values representing the amount of variance explained by all of the exogenous constructs ranging from 0 to 1 , with higher values indicating greater predictive accuracy. There are no generally accepted intervals for good coefficients of determination since they are specific to individual research disciplines [20]. Thus, we consider the intervals from Chin [22] used in explorative research cases. The limit starts at .190 , with values above this limit considered to have weak predictive accuracy, values above .330 moderate predictive accuracy and values above .670 very high predictive accuracy.

Self-assessed service performance shows a moderate predictive accuracy and thus is considered to be explained adequately by productivity (internal efficiency, external efficiency and capacitive efficiency) and complexity $\left(\mathrm{R}^{2}=.354\right)$.

The effect size $\mathrm{f}^{2}$ of exogenous constructs is regarded as another measure for evaluating predictive accuracy. The limits for small, medium and large effects are given as .02, .15 and .35 respectively [20]. The exogenous variables of internal and external efficiency plus capacitive efficiency are found to have a small effect on service performance. Furthermore, complexity shows a non-effect on the service performance $\left(\mathrm{f}^{2}=.016\right)$.

Finally, we evaluated predictive relevance $\left(\mathrm{Q}^{2}\right)$. The StoneGeissers $Q^{2}$ value assesses the fitness to rebuild the latent variable out of the associated indicators. Therefore, a value above zero is required. This final assessment criterion was also fulfilled with a value of .277 for the service performance variable.

\section{Discussion and Implications}

\subsection{Hypotheses}

In order to get a more sophisticated understanding of the interrelation of service productivity and service complexity, a total of four hypotheses were formulated. The results of the study show the importance of different efficiencies with regard to service performance. Both, internal (hypothesis 1) and external efficiency (hypothesis 2) are crucial to optimize service performance in medical rescue services. Hence, perceived customer satisfaction with service provision, or as in our case patient satisfaction, are just as equally important to service success as are internal processes.

However, capacity efficiency does not have a significant effect on service performance. Thus, hypothesis 3 cannot be confirmed. Since the setting of the described study was in medical rescue service, it was assumed that due to the importance of medical provision there would only be a theoretical resource limit which would be reached only in extreme situations. This assumption, however, does not hold true for the majority of service organizations in Germany. Limited resources can still be a limiting factor in service provision. Therefore, possible effects between capacitive efficiency and overloading of resources cannot be revealed in the present study and have to be addressed in future research in different settings.

Statistical analysis of hypothesis 4 indicated that, contrary to initial expectations, service complexity influences service performance positively. Again, as with hypothesis 3, a possible explanation for this finding might be in the special setting of the study. As a consequence of good education employees of medical rescue providers are well prepared to handle the often highly individual situations, so that increased complexity even with relatively unknown variables as electric vehicles seems to pose a challenge and increase service performance rather than deter it. This finding also has to be reexamined in future research. Moreover it is to be reflected, if complexity is just driven by a rising electro-mobility or if there are other factors that have a more significant impact on medical rescue service complexity.

\subsection{Implications for practitioners}

The results show a clear dependency between service productivity and performance. Surprisingly capacity efficiency does not influence medical rescue performance. Conversely, increases in complexity seem to have only a marginal though positive contribution on performance. 


\section{Harlacher et al. / Advances in Science, Technology and Engineering Systems Journal Vol. 2, No. 3, 427-434 (2017)}

According to the magnitude and significance of the path coefficients between the latent variables we distinguish a clear order in decreasing importance of the relationships. Internal efficiency is regarded to be of uttermost importance. Therefore practitioners should focus on increasing the efficiency of service provision by reducing disturbing factors and optimizing the process and information flow. Practitioners should install work structures that enable a smooth and interference-free service provision.

Second, external efficiency should be regarded as an important lever for improving medical rescue service performance. Key drivers are not necessarily in time arrival to the location of accident, but the utilization of effective and standardized procedures in order to safely rescue persons directly involved in an accident. The overall goal is to not only medically treat the patient but also taking care of him regarding any other aspects during the entire process of provision.

Last but not least there is - contrary to our expectations - no significant effect of capacity efficiency on performance. Thus, availability of personnel and material resources seems not to be an issue in medical rescue. The results suggest that performance is independent of the capacity utilized. This should be treated with caution, since it is possible that some other interaction effects were neglected or not considered at all in the study. For example it is not known whether the respondents were able to assess the capacity efficiency as the majority was not in a management position. Another possible explanation might be that there were no capacity problems and thus no influence on performance.

Complexity due to increased electric mobility is also of marginal impact on performance of rescue services. It is plausible that existing rescue procedures in Germany are also suitable and can be applied in mission which involves electric driven vehicles. Thus, an increase on complexity does not negatively impact performance. With existing skills and equipment the rescue personnel is able to fulfill a broader and more demanding rescue mission.

\subsection{Implication for future research}

The results of the analyses point out, that further research is needed. There is still little known about reliable measures for service productivity and complexity, especially in context of medical rescue services. In this paper a first approach for operationalizing service productivity and complexity was made. The results show that further in depth research for every single specific influencing factor on service performance is needed. Furthermore, different skill levels (with and without knowledge about electric driven vehicles as well as standardized procedures) and even different management levels should be considered and evaluated separately. Moreover, further research should also address patient in a dyadic survey.

The effect of complexity and capacity efficiency should be analyzed in more detail. It seems likely that linear models are unable to represent the real relationship between the constructs. Thus, novel approaches should be developed in order to operationalize these constructs as well as to analyze the impact on medical rescue performance.

\subsection{Limitations}

www.astesj.com
Despite the complexity of the developed measurement models and the limitation of extent of the questionnaire the reliability of the measurement model are on a sufficient level. Construct validity is also given on a sufficient level. Thus, the measurement of the latent variables has to be improved. Higher level of reliability and validity are desirable. On the one hand further investigations should stronger differentiate between internal and external efficiency of medical rescue services. On the other hand measurement models focusing on technical equipment and employees characteristics and influence on service productivity could be developed and proved.

Medical rescue services are unique caused by its framework conditions e.g. high individuality, federal financing models and deficient suggestibility of the content of the services. Thus, the transferability of the results to other kinds of services should be considered with caution. Moreover, the application to rescue service providers of other nationalities has to be evaluated.

\section{Conclusion}

Caused by the big impact of services generated in high-wage countries it is of utmost importance to increase service productivity and handle complexity. In order to do this service productivity and complexity have to be measured and evaluated. Based on extensive literature review a measurement model of service productivity was developed. The reliability and validity of this measurement models were demonstrated although there are still possibilities for improvement. A novel measurement model for service complexity was developed and is considered to be reliable and valid. To foster the measurement model and investigate possible nonlinear relationships between the constructs in more detail, further research is needed.

In the structural model evaluation a significant, positive relation between internal efficiency respective external efficiency and service performance is found. The dependency between capacitive efficiency and service performance is not significant. The positive influence of complexity on service performance should be investigated in more detail. Overall, by a focused productivity management the performance of medical rescue services can be increased accordingly.

\section{Conflict of Interest}

The authors declare no conflict of interest.

\section{Acknowledgment}

This research is funded by the German Federal Ministry of Education and Research (BMBF) within project SafetE-car "Scenarios Supported development of the service system - Secure supply in case of accidents and mishaps with electric vehicles" according to Grant No. 02K12A015 (formerly 01FE13009). Responsibility for the contents of this publication rests with the authors. The authors would like to express their gratitude for this support.

\section{References}

[1] Statistisches Bundesamt, "Bruttoinlandprodukt 2015 für Deutschland", Wiesbaden, p 11, 2016. 
[2] S. Bartsch, M. F. Demmelmair, A. Meyer, "Dienstleistungsproduktivität Stand der Forschung und Zusammenhang zu zentralen vorökonomischen Größen im Dienstleistungsmarketing“, Wiesbaden, NJ: Gabler, 2011.

[3] M. Nüttgens, O. Thomas, M. Fellmann, "Dienstleistungsproduktivität: Mit mobilen Assistenzsystemen zum Unternehmenserfolg", Wiesbaden, NJ: Springer, 2014.

[4] C. Grönroos, K. Ojasalo, "Service productivity - Towards a conceptualization of the transformation of inputs into economic results in services", in Journal of Business Research, Vol. 57, no. 4, pp. 414-423, 2004.

[5] M. Bruhn, M.O. Blockus, "Komplexität und Produktivität bei Dienstleistungen“, Wiesbaden, NJ: Gabler, pp. 59-87, 2011.

[6] J. Von Garrel, "Dienstleistungen produktiv erbringen: Eine empirische Analyse wissensintensiver Unternehmen in Deutschland", Wiesbaden, NJ: Gabler, 2014.

[7] Statistisches Bundesamt, Einsatzfahrtaufkommen im öffentlichen Rettungsdienst in Deutschland nach Einsatzart in den Jahren 1994 bis 2013", 2014.

[8] T. Levitt, "Production-Line Approach to Service", in: Harvard Business Review, Vol. 50 No. 5, 1972.

[9] P. Jones, "Quality, capacity and productivity in service industries", in: International Journal of Hopitality Management, Vol. 7, No. 2, pp. 104-112, 1988.

[10] H. Corsten, "Produktivitätsmanagement bilateraler personenbezogener Dienstleistungen", in: "Dienstleistungsproduktion: Absatzmarketing, Produktivität, Haftungsrisiken, Serviceintensität, Outsourcing”, pp. 43-77, 1994.

[11] R Johnston, P Jones, "Service Productivity - towards understanding the relationship between operational and customer productivity", International Journal of Productivity and Performance Management, Vol. 53, No. 3, pp. 201-213, 2004.

[12] K. Bleicher, "Das Konzept Integriertes Management: Visionen - Missionen Programme", Frankfurt am Main, NJ: Campus, 2011.

[13] D. Ahlert, H. Evanschitzky, J. Hesse, "Exzellenz in Dienstleistung und Vertrieb: Konzeptionelle Grundlagen und empirische Ergebnisse", Wiesbaden, NJ: Gabler, 2013.

[14] M. O. Blockus, "Komplexität in Dienstleistungsunternehmen Komplexitätsformen, Kosten- und Nutzenwirkungen, empirische Befunde und Managementimplikationen", Wiesbaden, NJ: Gabler, 2010.

[15] M. Bruhn, D. Georgi, "Services marketing”, Harlow, England London New York: Financial Times/Prentice Hall, an Imprint of Pearson Education, 2006.

[16] Ringle, C. M., Wende, S., and Becker, J.-M. 2015. "SmartPLS 3." Boenningstedt: SmartPLS GmbH, http://www.smartpls.com.

[17] K. Ojasalo, "Conceptualizing productivity in services", Helsingfors: Swedish School of Economics, 1999.

[18] C. Bliss, "Management von Komplexität: Ein integrierter, systemtheoretischer Ansatz zur Komplexitätsreduktion”. NJ: Springer 2013.

[19] Kraftfahrtbundesamt, "Jahresbilanz des Fahrzeugbestandes am 1. Januar 2017", Retrieved from http://www.kba.de/DE/Statistik/Fahrzeuge/Bestand/b_jahresbilanz.html;jses sionid=6240F6A000F3C10FCD49617694AC2577.live21304?nn=644526 $(15.05 .2017)$

[20] J. F. Hair, G. T. M. Hult, C. M. Ringle, M. Sarstedt, "A primer on partial least squares structural equation modeling (PLS-SEM)”. NJ: Sage, 2013.

[21] F. Huber, A. Herrmann, F. Meyer, J. Vogel, K. Vollhardt, "Kausalmodellierung mit Partial Least Squares - eine anwendungsorientierte Einführung", Wiesbaden, NJ: Gabler, 2007.

[22] W. Chin, "The Partial Least Squares Approach to Structural Equation Modeling", in: G.A. Marcoulides, "Modern Methods for Business Research", Mahwah, New Jersey, NJ: Lawrence Erlbaum Associates, 1998. 